\title{
Rachitic respiratory distress in small preterm infants
}

\author{
J. F. T. GLASGOW AND P. S. THOMAS
}

From the Department of Child Health, The Queen's University of Belfast, and Department of Radiology, Royal Maternity Hospital, Belfast

SUMMARY A syndrome of subacute respiratory distress, severe metabolic bone disease affecting the thoracic cage, and mild cholestasis occurred in 4 small preterm infants during the first three months of life and was associated with considerable morbidity. The early radiological features in the chest resembled those of the Mikity-Wilson syndrome, with which the disorder may be confused. After spontaneous improvement in hepatic function 3 of the infants fully recovered. The fourth died of paralytic ileus. Various nutritional and absorptive abnormalities probably contribute to the pathogenesis of the bone disorder in this syndrome. The best prophylaxis might be to supplement the diet with 25 -hydroxyvitamin $\mathrm{D}$ rather than native vitamin $\mathrm{D}$.

Respiratory difficulty is common during early infancy, particularly in preterm babies. Although often caused by a primary abnormality of the lungs or heart this is not invariably so. We report a subacute respiratory disorder in 4 small preterm infants associated with severe osteodystrophy of the thoracic cage. Although this disorder is not common it is probably being overlooked. Most of the cases have been reported in French papers (Rossier et al., 1958; Joseph et al., 1960; Lelong et al., 1961).

\section{Patients}

The infants born between 1967 and 1975, had a mean birthweight of $1.13 \mathrm{~kg}$ (Table 1). Cases 3 and 4 were below the 10th centile at birth (Gairdner and Pearson, 1971). Each of the pregnancies had been abnormal, 2 had been complicated by antepartum haemorrhages, one mother had severe pre-eclampsia, while the fourth was a grand multipara with triplets. The condition of the infants was good immediately

Received 12 July 1976 after delivery and none had asphyxia or respiratory difficulty. Initial feeds were evaporated milk fortified with vitamins. Additional vitamin D supplements were not given to Case 1, but Cases 2 and 4 received $10 \mu \mathrm{g}$ and Case $320 \mu \mathrm{g}$ daily.

Respiratory symptoms began while both Cases 1 and 4 were being investigated for mild obstructive jaundice, hepatomegaly, and splenomegaly. Rhesus incompatibility may have contributed to icterus in Case 4. Slow weight gain had already attracted attention in Cases 2 and 3.

Each of the infants developed gradually progressive respiratory distress, with a variable degree of expiratory wheezing, between 5 and 11 weeks of age. It was first thought that food had been aspirated, although in 2 infants the first chest radiographs had features suggestive of the Mikity-Wilson syndrome (MWS). On closer examination, however, each infant had evidence of craniotabes with an abnormally large, soft anterior fontanelle and some bony expansion at the wrists. Costochondral beading was not obvious. Coincidental with the onset of dysp-

Table 1 Clinical features of patients

\begin{tabular}{|c|c|c|c|c|c|c|c|}
\hline Case no. & Sex & $\begin{array}{l}\text { Birthweight } \\
(k g)\end{array}$ & $\begin{array}{l}\text { Gestational } \\
\text { maturity }(w)\end{array}$ & Pregnancy and delivery & $\begin{array}{l}\text { Apgar } \\
\text { score }(1 \mathrm{~min})\end{array}$ & $\begin{array}{l}\text { Respiratory } \\
\text { distress }\end{array}$ & $\begin{array}{l}\text { Age of } \\
\text { onset }(w)\end{array}$ \\
\hline 1 & $\mathbf{M}$ & $1 \cdot 80$ & 31 & $\begin{array}{l}\text { Para } 1 \text {, type II placenta } \\
\text { praevia, caesarean section }\end{array}$ & 9 & + & 10 \\
\hline 2 & $\mathbf{M}$ & 0.83 & 26 & $\begin{array}{l}\text { Primipara, antepartum } \\
\text { haemorrhage, normal } \\
\text { delivery }\end{array}$ & $\begin{array}{l}\text { Gasped at } \\
\text { birth }\end{array}$ & $+t$ & 10 \\
\hline 3 & $\mathbf{M}$ & $0 \cdot 71 *$ & 31 & $\begin{array}{l}\text { Para 1, pre-eclampsia, } \\
\text { normal delivery }\end{array}$ & 8 & $+t+$ & $\mathbf{5}$ \\
\hline 4 & $\mathbf{F}$ & $1 \cdot 19 *$ & 32 & $\begin{array}{l}\text { Para 9, } 1 \text { of triplets } \\
\text { normal delivery }\end{array}$ & 8 & + & 11 \\
\hline
\end{tabular}


noea Case 1 had a series of generalized seizures, found to be associated with profound hypocalcaemia and hypomagnesaemia.

Radiology. Radiographs of the chest showed diffuse patches of consolidation throughout both lungs and varying degrees of hyperinflation (Table 2). Definite cystic changes were present in the right lower zone in Case 2 (Fig.). More obvious, however, was the presence of severe skeletal demineralization, which was generalized in 3 infants. These features, particularly evident in the ribs and shoulder girdle, were most severe in Case 3. Many fresh and healing rib fractures were seen in Cases 1, 2 (Fig.), and 4. In Case 2 there were also multiple fractures of the long bones of the arms and legs. Rachitic changes were present in each of the infants, seen best at the lower radial and ulnar metaphyses and in the skull. These changes were also noted in the inferior angles of the scapulae in Case 1.

In 3 infants a layer of periosteal new bone was discernible along the inferior and lateral aspects of the ascending and horizontal rami of the mandible. Similar periosteal new bone formation was present in the shafts of the long bones and ribs. Radiographic details of Case 1 have been reported (Thomas and Glasgow, 1974).

Laboratory investigations. Each patient had biochemical evidence of obstructive jaundice (Table 3).

Table 2 Radiological features at onset of respiratory distress

\begin{tabular}{|c|c|c|c|c|c|c|c|}
\hline \multirow[b]{2}{*}{ Case no. } & \multicolumn{3}{|l|}{ Lungs } & \multicolumn{4}{|l|}{ Skeleton } \\
\hline & Consolidation & Overinflation & Cysts & Fractures & Demineralization & Rickets & $\begin{array}{l}\text { Mandibular } \\
\text { periosteal new } \\
\text { bone }\end{array}$ \\
\hline 1 & + & + & - & Ribs & Axial & + & + \\
\hline 2 & + & + & + & $\begin{array}{l}\text { Ribs and } \\
\text { long bones }\end{array}$ & Generalized & + & + \\
\hline 3 & + & + & - & None & Generalized & + & + \\
\hline 4 & + & - & - & Ribs & Generalized & + & - \\
\hline
\end{tabular}

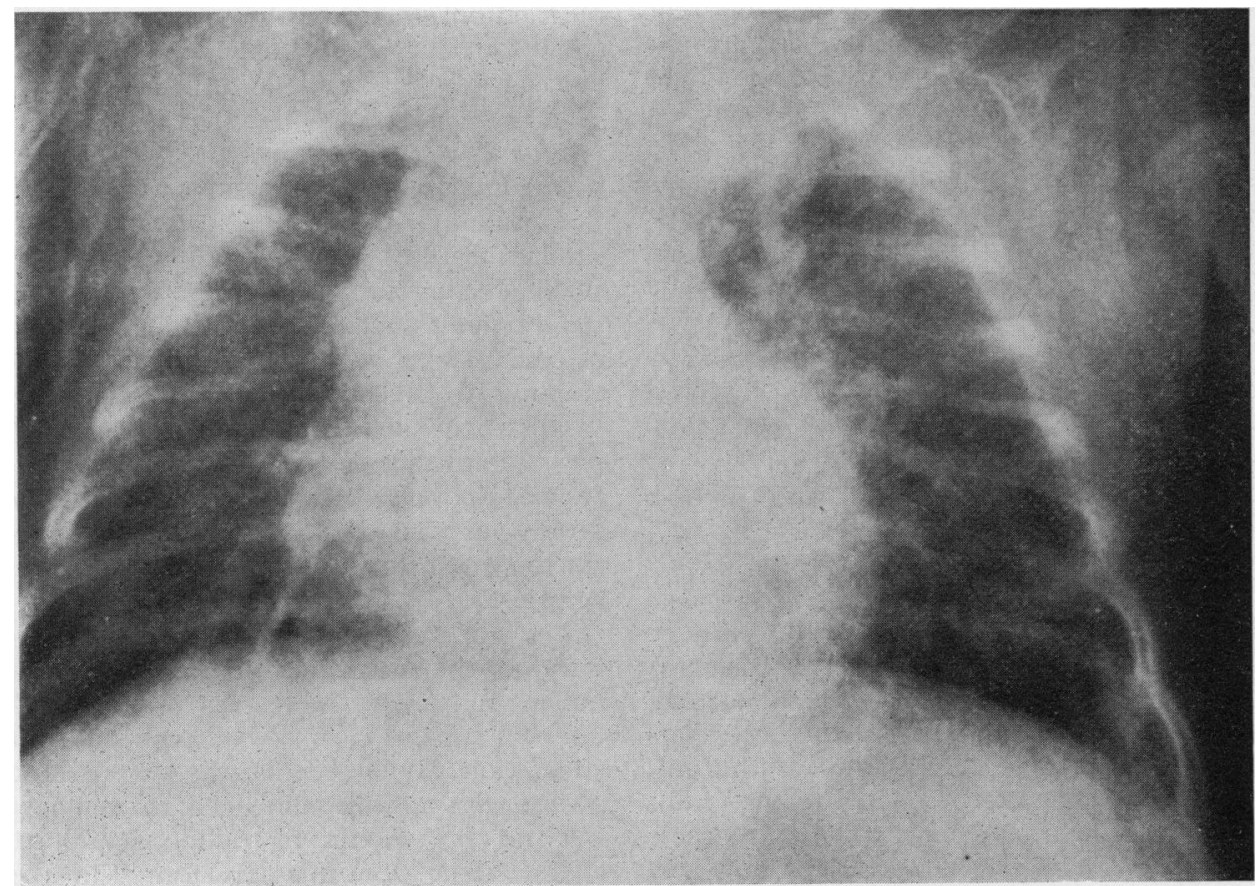

Fig. Case 2. Radiograph of chest showing severe skeletal demineralization, recent fractures of 6 th and 7 th ribs left, fracture of 6th rib right, fairly extensive areas of consolidation in both lungs, and cystic changes in right lower zone. 
Table 3 Laboratory data at onset of respiratory distress

\begin{tabular}{|c|c|c|c|c|c|c|c|}
\hline \multirow[t]{2}{*}{ Case no. } & \multicolumn{2}{|c|}{ Bilirubin ( $\mu$ mol/l) } & \multirow{2}{*}{$\begin{array}{l}\text { Alkaline } \\
\text { phosphatase } \\
(K A U)\end{array}$} & \multirow{2}{*}{$\begin{array}{l}\text { Calcium } \\
(\mathrm{mmol} / \mathrm{l})\end{array}$} & \multirow{2}{*}{$\begin{array}{l}\text { Inorganic } \\
\text { Phosphate } \\
(\mathrm{mmol} / \mathrm{l})\end{array}$} & \multirow{2}{*}{$\begin{array}{l}\text { Maximum } \\
\text { duodenal bile } \\
\text { salts (mmol/l) }\end{array}$} & \multirow{2}{*}{$\begin{array}{l}\text { Faecal } \\
\text { fat }(\% \text { diet })\end{array}$} \\
\hline & Total & Direct & & & & & \\
\hline $\begin{array}{l}1 \\
2 \\
3 \\
4\end{array}$ & $\begin{array}{r}108 \\
77 \\
63 \\
108\end{array}$ & $\begin{array}{l}82 \\
37 \\
29 \\
76\end{array}$ & $\begin{array}{l}66 \\
55 \\
47 \\
54\end{array}$ & $\begin{array}{l}1 \cdot 65 \\
1 \cdot 80 \\
1 \cdot 43 \\
1 \cdot 70\end{array}$ & $\begin{array}{l}1 \cdot 26 \\
1 \cdot 29 \\
2 \cdot 33 \\
1 \cdot 23\end{array}$ & $\begin{array}{l}0.75 \\
0 \cdot 53 \\
0.22 \\
-\quad\end{array}$ & $\begin{array}{l}25 \\
35 \\
30 \\
-\end{array}$ \\
\hline
\end{tabular}

Conversion : SI to traditional units-Bilirubin: $1 \mu \mathrm{mol} / 1 \approx 0.1 \mathrm{mg} / 100 \mathrm{ml}$.

Calcium: $1 \mathrm{mmol} / 1 \approx 4 \mathrm{mg} / 100 \mathrm{ml}$. Inorganic phosphate $1 \mathrm{mmol} / 1 \approx 3.01 \mathrm{mg} / 100 \mathrm{ml}$.

In 2 duodenal intubation showed a very low maximum postprandial bile salt concentration. Steatorrhoea, as measured by a formal 3- or 5-day fat balance, was present in the 3 infants tested. The serum alkaline phosphatase concentration was raised in each infant, while in 3 the calcium level was less than $1.75 \mathrm{mmol} / 1(7.0 \mathrm{mg} / 100 \mathrm{ml})$. Cases 1 and 4 were hypophosphataemic.

Aminoaciduria was a constant feature: it was of generalized type in 3 infants and was associated with an increased excretion of proline and hydroxyproline. Tyrosyluria was present in 2 babies. The plasma amino acids were measured in 2 patients. In Case 1 there was a generalized rise in amino acids while in Case 4 the tyrosine and methionine were raised. Guthrie tests in Cases 2 and 3 showed tyrosine concentrations in excess of $1105 \mu \mathrm{mol} / 1$ at 2 and 4 weeks of age. Such findings are not uncommon in preterm infants with cholestasis and should not be confused with hereditary tyrosinaemia ( $\mathrm{Yu}$ et al., 1971a).

No specific aetiology for the cholestasis was found in any of the infants; in particular transplacental infections, $\alpha_{1}$-antitrypsin deficiency, hereditary tyrosinaemia, galactosaemia, and cystic fibrosis were excluded.

Arterial blood gas determinations during the period of respiratory distress in Cases 2 and 3 showed the presence of a moderate metabolic acidaemia ( $p \mathrm{H} \mathrm{7.31}$ and 7.30; $\mathrm{Po}_{2} 11 \cdot 70$ and 10.92 $\mathrm{kPa}(87.7$ and $81.9 \mathrm{mmHg}))$ with compensatory respiratory alkalaemia $\left(\mathrm{PCO}_{2} 4.39\right.$ and $3.07 \mathrm{kPa}$ $(32.9$ and $23.02 \mathrm{mmHg})$ ).

Clinical course Cases 1, 2, and 4. Respiratory difficulty lasted between 3 and 10 weeks, during which the rate of weight gain was subnormal. Apnoeic attacks occurred in each patient, necessitating constant monitoring. The severity of the pulmonary disorder seemed to be related to the radiological severity of the osteodystrophy of the thoracic cage. As bone mineralization improved, however, and rib fractures healed respiratory function recovered. During this time Cases 1 and 2 were treated with parenteral vitamin $\mathrm{D}, 20$ and $50 \mu \mathrm{g}$ respectively; Case 4 had oral vitamin D $125 \mu \mathrm{g}$ daily.

Case 3. This infant, the smallest of the 4 , was also light for dates. Apnoeic episodes were particularly severe and weight remained stationary. Tube feeds were not tolerated and intravenous fluids were started. Intramuscular vitamin $\mathbf{D}$ and calcium were given but respiration did not improve and the chest $x$-ray findings remained unchanged. In view of the child's poor condition parenteral antibiotics were given. Whenever small amounts of oral feeding were reintroduced the baby developed abdominal distension and vomiting. Radiographs of the abdomen showed dilated loops of lower small gut. At exploratory laparotomy, however, no localized obstruction could be found. Postoperatively his condition deteriorated further and he died three days later aged 9 weeks.

Necropsy findings. Abnormalities were noted in the bones, lungs, and liver. Sections were examined from the cranium, vertebrae, ribs, and femur. Largely similar features were noted in each, the most striking being excessive proliferation of the subperiosteal bone associated with moderate amounts of osteoid. There was a proliferative change in the epiphyseal cartilage with some widening of the vascular channels. Endochondral ossification was proceeding and the bony trabeculae thus formed showed the presence of mildly increased amounts of poorly ossified osteoid. There were no microfractures seen in the region of the epiphyseal plate. Mild osteoporosis was present.

The lungs showed no gross lesions. The pleura were not thickened and showed no emphysematous bullae. In general there was moderate and fairly uniform expansion of alveoli with mild pulmonary congestion. Some oedema was also present in association with variable numbers of macrophages. There was no pneumonia or pulmonary fibrosis. The characteristic abnormalities found in the MWS, including focal atelectasis and emphysema, were not found (Kissane, 1975). The bronchovascular tree 
was unremarkable with no evidence of bronchitis or aspiration.

The liver (weight $90 \mathrm{~g}$ ) was bile stained on section. The extrahepatic biliary system was patent; the gallbladder contained normal bile. Histologically the hepatocytes were swollen and there were numerous bile plugs throughout the lobules. No intracellular inclusions, giant cells, or pseudoacinae were seen. Accumulations of haemopoietic cells were obvious. In the portal tracts no inflammatory infiltrate or bile duct proliferation was noted. The pancreas was normal and the bowel, though dilated, was unremarkable.

\section{Discussion}

The nature of the pulmonary changes in these four preterm infants were such that in 2 of them a diagnosis of MWS was initially thought likely. More noteworthy than the pulmonary abnormalities, however, was the severe demineralization of the skeleton. This was identified as being osteomalacic in nature both biochemically and, in Case 3, histologically. Therefore with respect to these two findings-namely, mildly abnormal lungs but grossly disturbed bones, both within the rib cage and throughout the skeleton -the patients bear some resemblance to the infants described by Griscom et al. (1971).

Rib fractures have been reported occasionally in MWS (Mikity et al., 1967). The severity of the bone disease in our infants, however, and the disparity in the necropsy findings between the marked bone changes and the relatively mild lung findings in Case 3 tend to support our view that the primary abnormality was skeletal. The pulmonary changes are attributed to impaired respiratory movement brought about by softening and fracturing of the ribs as well as weakness of the respiratory muscles. The myopathy of severe osteomalacia may be the result of very low plasma levels of 1,25-dihydroxyvitamin $\mathrm{D}$. This metabolite, thought to have a major part in the movement of calcium ions across cell membranes in both gut and kidney, may have a similar function in moving calcium into skeletal muscle cells (Schott, and Wills, 1976). The muscle lesion as well as playing a role in the development of the respiratory disorder may also have contributed to the development of paralytic ileus in the infant who died.

There have been few English reports about this form of lung disease in small preterm infants. Boissière et al. (1964) reviewed French experience. Several monographs on childhood respiratory disorders and neonatal medicine make no reference to it (Schaffer and Avery, 1971; Kendig, 1972; Avery and Fletcher, 1974; Williams and Phelan,
1975). This might be because the true nature of the disorder goes unrecognized. In 2 of our patients the radiographic findings at the onset of dyspnoea could easily have been confused with those found in the initial stages of MWS. Evidence of established metabolic bone disease was already present, however, suggesting that the pulmonary changes were secondary to demineralization of the thoracic cage. Furthermore the classical features of MWS never developed and clearing of the lungs closely paralleled skeletal healing. Likewise, 2 of the 3 infants of Griscom et al. (1971) were thought to have features of the MWS at a time when bone disease was already well established. Necropsy findings in their patient who died showed very modest lung lesions, which was in striking contrast to the skeletal lesions.

The incidence of MWS has been estimated to be 1 in 450 preterm infants (Mikity et al., 1967). During the 7-year period of this study only 2 patients with classical MWS were seen in 2000 preterm infants in the same nursery population. If, however, the 2 patients with metabolic bone disease, each of whom had initial features suggesting MWS, are included the incidence becomes 1 in 500. Possibly, therefore, some series of MWS may include patients in whom metabolic bone disease was the primary lesion. Among 20 low birthweight infants with 'pulmonary insufficiency' Burnard et al. (1965) reported that 4 had rib fractures and 3 of these also had rickets.

The association of pulmonary abnormality and bone disease in small preterm infants should prompt the clinician to look for evidence of cholestasis (Lelong et al., 1961). Although obstructive jaundice may be subclinical, a clue to its presence is bronze skin pigmentation ( $\mathrm{Yu}$ et al., 1971a) which was present in 3 of our patients. This was also reported in 4 of the patients of Burnard et al. (1965) and, although it is not clear whether these were the same infants found to have bone disease, from the published details this is possible.

The pathogenesis of bone disease in these infants is probably related to a variety of metabolic and nutritional factors. Although an abnormality of vitamin D metabolism is probably of prime importance Griscom et al. (1971) pointed out that some of the findings in their infants bear a resemblance to copper deficiency (Cordano et al., 1964). Hence nutritional factors may play a part. With regard to vitamin D metabolism, it has been shown that the concentration of 25-hydroxyvitamin D (25-OHD) in maternal plasma governs the levels in cord blood (Hillman and Haddad, 1974); Rosen et al., 1974). Furthermore, in very immature preterm infants profoundly low plasma concentrations of 25-OHD have been reported between 6 and 8 weeks of age 
(Hillman and Haddad, 1975). This corresponds to the age at which our infants began to develop respiratory distress.

Mild rickets unassociated with lung involvement has also been described in small preterm newborns fed a vitamin D fortified milk formula (Lewin et al., 1971). Bone disease was attributed to the fact that none of these infants had been given additional vitamins. Since the volume of fortified milk ingested was small the intake of vitamin $D$ was particularly low. Dietary deficiency was a contributory factor in Case 1.

In contrast with mild rickets in Lewin's babies, 3 of our patients developed severe, widespread, symptomatic bone disease despite being supplemented with vitamin $D$ from birth. This may suggest that there was malabsorption of vitamin $D$. In support of this is the finding of profoundly low bile salt concentrations during digestion. In obstructive jaundice levels well below those required for micellarization of lipolysed dietary fat are present and associated with steatorrhoea (Glasgow et al., 1973). Badley et al. (1969) have shown that bile salt concentrations in excess of $4 \mathrm{mmol} / 1$ are required for normal fat absorption. Since nonpolar lipids such as vitamin D are even more dependent upon intraluminal micellar solubilization than dietary triglyceride considerable malabsorption of fat-soluble vitamins seems virtually certain (Thompson, 1971).

The presence of intrahepatic cholestasis may be associated with impaired 25-hydroxylation of native vitamin D within the liver (Yu et al., 1971b). It has been shown that even in normal preterm infants both oral and intravenous vitamin $D$ failed to raise the plasma concentration of 25-OHD (Hillman and Haddad, 1975). Hence in terms of the duration of a hydroxylation defect the small preterm infant with additional intrahepatic dysfunction may be at a particular disadvantage.

Since the plasma concentration of maternal 25OHD governs that of the infant at birth, adequate prophylaxis in infants of this maturity can be achieved only by supplementing with vitamin $D$ the diet of mothers thought to have a high risk of preterm delivery. A more practical alternative, however, might be to supplement all such newborns themselves with 25-OHD.

We thank Professor I. J. Carré and Dr. W. A. B. Campbell for permission to report these patients, Dr. Denis O'Hara for giving the details and discussing the pathology in Case 3, and Mrs. Joan Blair and Miss Denise McAfee for secretarial assistance. Aspects of this work were supported by the Children's Research Fund, Liverpool.

\section{References}

Avery, M. E., and Fletcher, B. D. (1974). The Lung and its Disorders in the Newborn Infant, 3rd ed. Saunders, Philadelphia.

Badley, B. W. D., Murphy, G. M., and Bouchier, I. A. D. (1969). Intraluminal bile-salt deficiency in the pathogenesis of steatorrhoea. Lancet, 2, 400-402.

Boissière, H., Cagnat, R., Poissonnier, M., and d'Angely, S. (1964). Dystrophie oestéomalacique du prématuré. Annales de Pédiatrie, 11, 367-383.

Burnard, E. D., Grattan-Smith, P., Picton-Warlow, C. G., and Grauaug, A. (1965). Pulmonary insufficiency in prematurity. Australian Paediatric Journal, 1, 12-38.

Cordano, A., Baertl, J. M., and Graham, G. G. (1964). Copper deficiency in infancy. Pediatrics, 34, 324-336.

Gairdner, D., and Pearson, J. (1971). A growth chart for premature and other infants. Archives of Disease in Childhood, 46, 783-790.

Glasgow, J. F. T., Hamilton, J. R., and Sass-Kortsak, A. (1973). Fat absorption in congenital obstructive liver disease. Archives of Disease in Childhood, 48, 601-607.

Griscom, N. T., Craig, J. N., and Neuhauser, E. B. D. (1971). Systemic bone disease developing in small premature infants. Pediatrics, 48, 883-895.

Hillman, L. S., and Haddad, J. G. (1974). Human perinatal vitamin D metabolism. I. 25-hydroxyvitamin D in maternal and cord blood. Journal of Pediatrics, 84, 742-749.

Hillman, L. S., and Haddad, J. G. (1975). Perinatal vitamin D metabolism. II. Serial 25-hydroxyvitamin D concentrations in sera of term and premature infants. Journal of Pediatrics, 86, 928-935.

Joseph, R., Nezelof, C., Ribierre, M., Job, J. C., and Debauchez, C. (1960). Le retentissement respiratoire du rachitisme thoracique. Annales de Pédiatrie, 7, 537-548.

Kendig, E. L. (1972). Disorders of the Respiratory Tract in Children, 2nd ed. Saunders, Philadelphia.

Kissane, J. M. (1975). Pathology of Infancy and Childhood, 2nd ed., p. 493. Mosby, St. Louis.

Lelong, M., Alagille, D., and Robineau-Bagot. T. (1961). L'hépatite néonatale du prématuré avec pneumopathie subaiguë et rachitisme précoce. Etude de 17 observations. Revue Internationale d'Hépatologie, 11, 793-836.

Lewin, P. K., Reid, M., Reilly, B. J., Swyer, P. R., and Fraser, D. (1971). Iatrogenic rickets in low-birth-weight infants. Journal of Pediatrics, 78, 207-210.

Mikity, V., Hodgman, J. E., and Tatter, D. (1967). The radiological findings in delayed pulmonary maturation in premature infants. Progress in Pediatric Radiology, Vol. 1, p. 149. Ed. by H. J. Kaufman. Karger, Basel.

Rosen, J. F., Roginsky, M., Nathenson, C., and Finberg, L. (1974). 25-hydroxyvitamin D: plasma levels in mothers and their premature infants with neonatal hypocalcemia. American Journal of Diseases of Children, 127, 220-223.

Rossier, A., Paupe, J., Michelin, J., and Larnaudie, J. (1958). Dystrophie osseuse ostéomalacique chez d'extrêmes prématurés. Archives Françaises de Pédiatrie, 15, 477-498.

Schaffer, A. J., and Avery, M. E. (1971). Diseases of the Newborn, 3rd ed. Saunders, Philadelphia.

Schott, G. D., and Wills, M. R. (1976). Muscle weakness in osteomalacia. Lancet, 1, 626-628.

Thomas, P. S., and Glasgow, J. F. T. (1974). Bone disease in infants with prolonged obstructive jaundice. Pediatric Radiology, 2, 125-132.

Thompson, G. R. (1971). Absorption of fat-soluble vitamins and sterols. Journal of Clinical Pathology, 24, Suppl. 5, 85.

Yu, J. S., Walker-Smith, J. A., and Burnard, E. D. (1971a). Neonatal hepatitis in premature infants simulating hereditary tyrosinosis. Archives of Disease in Childhood, 46, 306-309. 
Yu, J. S., Walker-Smith, J. A., and Burnard, E. D. (1971b). Correspondence to Dr. J. F. T. Glasgow, DepartRickets: a common complication of neonatal hepatitis. Medical Journal of Australia, 1, 790-792.

Williams, H. E., and Phelan, P. D. (1975). Respiratory Illness in Children. Blackwell, Oxford.

ment of Child Health, Institute of Clinical Science, Grosvenor Road, Belfast BT12 6BJ, Northern Ireland. 